\title{
Tacrolimus inhibits intimal hyperplasia in arterialised veins in rats
}

\author{
Varga $\mathrm{M}^{1}$, Matia $\mathrm{I}^{2}$, Lodererova $\mathrm{A}^{3}$, Adamec $\mathrm{M}^{1}$ \\ Transplant Surgery Department, Institute for Clinical and Experimental Medicine, Prague, Czech Republic. \\ ivmi@ikem.cz
}

\begin{abstract}
Objectves: We investigated whether tacrolimus (FK506) can inhibit neointimal formation in arterialised vein grafts in rats.

Methods: Lewis iliolumbar veins were implanted into the abdominal aorta of isogeneic rats. Animals in the treatment groups had daily intramuscular injections of tacrolimus at $0.2 \mathrm{mg} / \mathrm{kg}$ (group B) and $0.1 \mathrm{mg} / \mathrm{kg}$ (Group C), respectively. The control group A had no treatment. Light microscope evaluations of arterialised vein grafts were performed 30 days after operation. We determined the presence of endothelial cells, the thickness of intima and media, and the degree of infiltration by MHC class II positive, CD4 positive, and CD8 positive cells into the adventitia.

Results: The intimal thickness in group $B(5.0 \pm 1.0 \mu \mathrm{m})$ was statistically lower $(P<0.05)$ when compared to group $C(7.0 \pm 3.0 \mu \mathrm{m})$. The intimal thickness in untreated group $A(12.7 \pm 7.0 \mu \mathrm{m})$ was statistically higher $(P<$ 0.01 ) when compared to both treated groups B and C, respectively. The medial thickness and degree of adventitial infiltration by MHC class II positive, CD8 positive, and CD4 positive cells did not differ between groups. Conclusion: Treatment with tacrolimus (FK506) showed a dose dependant inhibition of neointimal hyperplasia in arterialised vein grafts in rats (Tab. 1, Fig. 3, Ref. 22). Full Text in free PDF www.bmj.sk. Key words: intimal hyperplasia, tacrolimus, FK506; rats.
\end{abstract}

Saphenous vein grafts are a material of choice for peripheral vascular reconstruction in the surgical treatment of peripheral arterial occlusive disease. Late failure of saphenous vein grafts develops as a result of intimal hyperplasia which is characterized by cell proliferation and extracellular matrix synthesis with subsequent accelerated atherogenesis (1). It has been shown that the level of intimal hyperplasia is directly linked to the degree of endothelial denudation, which, in vein grafts is caused by luminal distension during surgery, ischemia, damage at surgical anastomoses and continued physical trauma under arterial conditions (2-4). Moreover arterial tangential pressure, medial damage and thickening as well as shear stress changes and altered flow patterns are involved in the development of intimal hyperplasia (5-7).

All these new findings in pathophysiology of intimal hyperplasia led to the development of many new therapeutic agents

${ }^{1}$ Transplant Surgery Department, Institute for Clinical and Experimental Medicine, Prague, Czech Republic, ${ }^{2}$ Universitätsklinikum Leipzig AöR, Department für Operative Medizin, Klinik und Poliklinik für Viszeral-, Transplantations-, Thorax- und Gefäßchirurgie, Leipzig, Deutschland, and ${ }^{3}$ Department of Pathology, Institute for Clinical and Experimental Medicine, Prague, Czech Republic

Address for correspondence: I. Matia MD, PhD, Universitätsklinikum Leipzig AöR, Department für Operative Medizin, Klinik und Poliklinik für Viszeral-, Transplantations-, Thorax- und Gefäßchirurgie, Liebigstrasse 20, D-04103 Leipzig, Deutschland.

Phone: +420.2.61364105, Fax: +420.2.61362822

Acknowledgement: The work was supported by Grant No. MZO 00023001 awarded by Ministry of Health of the Czech Republic. aimed at treating this condition (1). However, the successes of laboratory studies have not been implicated in the clinic largely. Exception from this are drug-eluting stents used in percutaneous coronary interventions for the treatment of coronary stenosis (8, 9). Several clinical trials have demonstrated that sirolimus-eluting stents and paclitaxel-eluting stents are superior to bare metal stents by decreasing the restenosis rates as well as major adverse cardiac events $(10,11)$. However, stent thrombosis after 1 year was more common with both sirolimus-eluting stents and paclitaxeleluting stents than with bare metal stenos (12). The reason for it was that both types of drug-eluting stents caused significant delay in arterial healing characterised by persistent fibrin deposition and delayed re-endothelialisation when compared to bare metal stents. Recently a new generation of tacrolimus-eluting stents has been developed and investigated in animal experiments with good results (13).

Tacrolimus (FK506) and sirolimus (rapamycin) are macrolide antibiotics with immunosuppressive and both anti-proliferative and anti-inflammatory activity commonly used in transplanted patients after solid organ transplantation $(14,15)$. Tacrolimus is less potent than sirolimus for inhibiting vascular smooth muscle cell proliferation or migration (16). However, tacrolimus was reported to have less anti-proliferative effect on cultured endothelial cells compared to sirolimus (17). In a porcine coronary model, the degree of re-endothelialisation was similar with tacrolimuseluting stent and bare metal stents (13). Therefore, tacrolimus is suggested to be a promising compound for the next generation of drug-eluting stents (13). 
In our own experiments we have used tacrolimus in rats after arterial and venous transplantations. Tacrolimus administered intramuscularly was sufficient to suppress acute rejection changes and inhibit intimal proliferation in aortal allografts (18). In addition, we have proven the positive effect of tacrolimus on the wall-remodelling process of venous allografts following their implantation into the arterial system (19).

The purpose of this study was to study the effect of systemic tacrolimus treatment on neointimal hyperplasia and medial thickening using a rat vein-to-artery implantation model.

\section{Methods}

Principles of laboratory animal care were followed, and applicable national laws observed during the study.

\section{Animals}

Male Lewis rats (LEW) $\left(\mathrm{RT} 1^{1}\right)$ weighing 200 to $330 \mathrm{~g}(\mathrm{n}=27)$ were used in the study. Nine Lewis rats were used as donors and eighteen Lewis rats were used as recipient of iliolumbar vein grafts. Animals were obtained from Charles River, Germany. All the rats were maintained according to the National Institute of Health guidelines. Each transplanted animal was held separately in a confinement cage during the entire follow-up period.

\section{Operative procedure}

The operative procedure was the same as used in our previous experiment with venous transplantation in rats (19). Briefly, the donor animals were anesthetized by an intramuscular injection of ketamine (Narkamon ${ }^{\circledR}$, Spofa a.s., Prague, Czech Republic) at $100 \mathrm{mg} / \mathrm{kg}$ and xylazine (Rometar ${ }^{\circledR}$, Spofa a.s., Prague, Czech Republic) at $10 \mathrm{mg} / \mathrm{kg}$. Two 1-1.5 cm long segments of the iliolumbar veins were excised and stored in saline solution at room temperature until their transplantation. The mean ischemic time for the vein grafts was 172 minutes, with no statistical differences between the experimental groups.

The recipient animals were anesthetized with an intramuscular injection of sufentanil (Sufenta ${ }^{\circledR}$, Janssen Pharmaceutica Inc., Beerse, Belgium) at $20 \mu \mathrm{g} / \mathrm{kg}$ and azaperone (Stresnil ${ }^{\circledR}$, Janssen Pharmaceutica Inc., Beerse, Belgium) at $1 \mathrm{mg} / \mathrm{kg}$. After a midline laparotomy, the venous grafts were implanted with a running 10-0 mono-filament suture (Ethicon Inc., Sommerville, New Jersey, USA). into the recipients infrarenal aorta.

Neither anti-coagulants nor anti-platelet drugs were used in this experiment.

\section{Animal groups}

The recipient animals were divided into three groups. Animals in the treatment groups had daily intramuscular injections of tacrolimus at $0.2 \mathrm{mg} / \mathrm{kg}$ (group $\mathrm{B}, \mathrm{n}=6$ ) and $0.1 \mathrm{mg} / \mathrm{kg}$ (group $C, n=6)$, respectively. The control group $A(n=6)$ had no treatment.

The rats in presented study were operated as a part of larger rat venous transplantation study. In this whole experiment only one syngeneic control group A (no treatment) was operated. The group B and C results in this work are compared to original control group A results (19).

\section{Immunosuppressive therapy}

The immunosuppressive protocol in presented syngeneic veinto-artery model was the same as that in the allogeneic model. Briefly, treated animals received intramuscularly in saline solution suspended tacrolimus (Prograf ${ }^{\circledR}$, Astellas Pharma Inc., Tokyo, Japan) at $0.2 \mathrm{mg} / \mathrm{kg} /$ day (group B) and $0.1 \mathrm{mg} / \mathrm{kg}$ (group C), respectively. Immunosuppression begun on day 1 after transplantation and was administered for the whole 30 day follow-up period. On day 30, tacrolimus blood levels were evaluated in both groups using an enzyme enhanced immunoassay technique (Emit ${ }^{\circledR} 2000$ Tacrolimus assay, Dade Behring Inc., Deerfield, Illinois, USA) Venous grafts were removed after a midline re-laparotomy and processed for histology and immunohistochemistry. The animals were euthanized by intracaval administration of a lethal dose of thiopental (Thiopental ${ }^{\circledR}$, Spofa, a.s., Prague, Czech Republic).

\section{Histology and immunohistochemistry}

Histologic and immunohistochemical analyses were performed according to the methods described previously in our allogeneic vein-to-artery transplantation model (19). Briefly, after harvest were the venous grafts embedded in Sakura Finetek Tissue Tek $₫$ Cryomold holders (Sakura Finetek, Tokyo, Japan) and Sakura Finetek Tissue Tek@ O.C.T. compound (Sakura Finetek, Tokyo, Japan). The samples were then subsequently frozen in 2-methylbutane (Fluka Chemika, Buchs, Switzerland) cooled by liquid nitrogen and stored till processed at $-80^{\circ} \mathrm{C}$.

\section{Histologic analysis}

Digital image analysis was used to quantify the intimal hyperplasia as described previously (19). Briefly, frozen cross sections $(5 \mu \mathrm{m})$ from the midportion of the graft were stained with a Hematoxylin \& Eosin and a Van Gieson with elastica stain. Each section was photographed with an Olympus Cammedia C-5050 digital camera (Olympus, Hamburg, Germany) and analyzed with Olympus DP-Soft software version 3.2. Measurements for intimal (from the endothelial surface to the inner border of the tunica media) and medial thickness (from the inner to the outer border of the tunica media) were made in blinded fashion in up to 10 locations in each section. The mean value and standard deviation (mean \pm SD) were calculated for each vein and each animal group.

\section{Immunohistochemical analysis}

Detection of CD4+ cells,CD8+ cells, and Von Willebrand factor

Immunohistochemistry was performed on $8 \mu \mathrm{m}$ thick sections with a two-step indirect method as described previously (19). Briefly, after 10 min fixation in cold acetone and rinsing in $0.2 \%$ Triton X 100 and phosphate-buffered saline, the sections were incubated with a primary antibody (anti-CD4 (W3/25, Cymbus Biotechnology LTD, Hampshire, UK), anti-CD8 (OX-8, Cymbus Biotechnology LTD, Hampshire, UK), anti-Von Willebrand factor (Dako Denmark A/S, Glostrup, Denmark) for 60 min. After blocking of endogenous peroxidase activity by 30 min incubation 


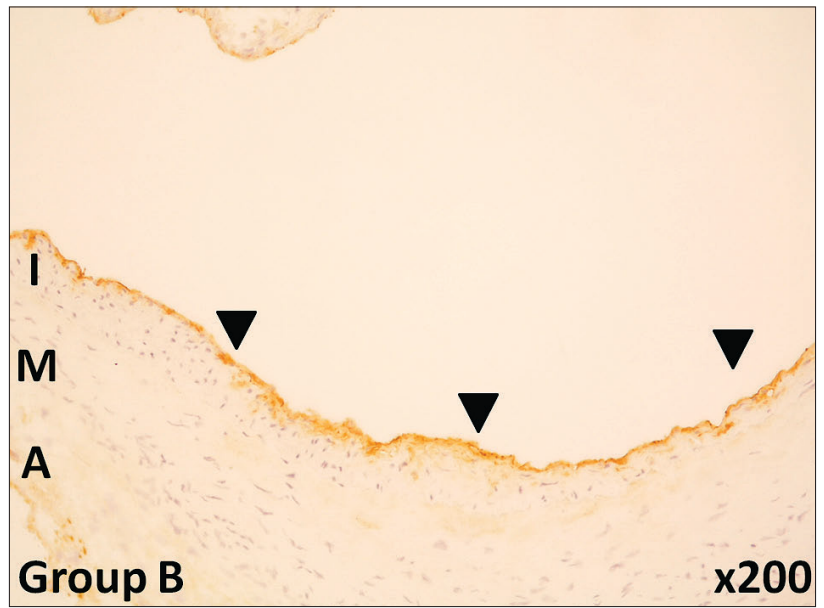

Fig. 1. Representative light microscopic features of vein treated with tacrolimus at higher dose (group B) obtained 30 days after implantation to the infrarenal abdominal aorta. Immunostaining with antiVon Willebrand factor antibody. Positive endothelial cells are stained brown (black marks).

I - tunica intima, $\mathrm{M}$ - tunica media, A - tunica adventitia.

in $0.3 \% \mathrm{H}_{2} \mathrm{O}_{2}$ and $70 \%$ methanol, the sections were incubated with a secondary antibody (Histofine ${ }^{\circledR}$ Simple Stain Rat MAX PO, Nichirei, Japan) for $30 \mathrm{~min}$ and then incubated with Dako Liquid DAB+ Substrate-Chromogen System (Dako Denmark A/S, Glostrup, Denmark) for 5 minutes. Finally, the specimens were counterstained and dipped in Entellan@ (Merck KGaA, Darmstadt, Germany) and scored in a blinded fashion. Cells were counted at 5 locations at x1000 magnification and the cellularity was defined as the mean value of the cells counted.

Detection of Lewis MHC class II positive cells

Immunohistochemistry was performed on $8 \mu \mathrm{m}$ thick sections with a three-step indirect method as described previously (19). Briefly, after 10 min fixation in cold acetone and rinsing in

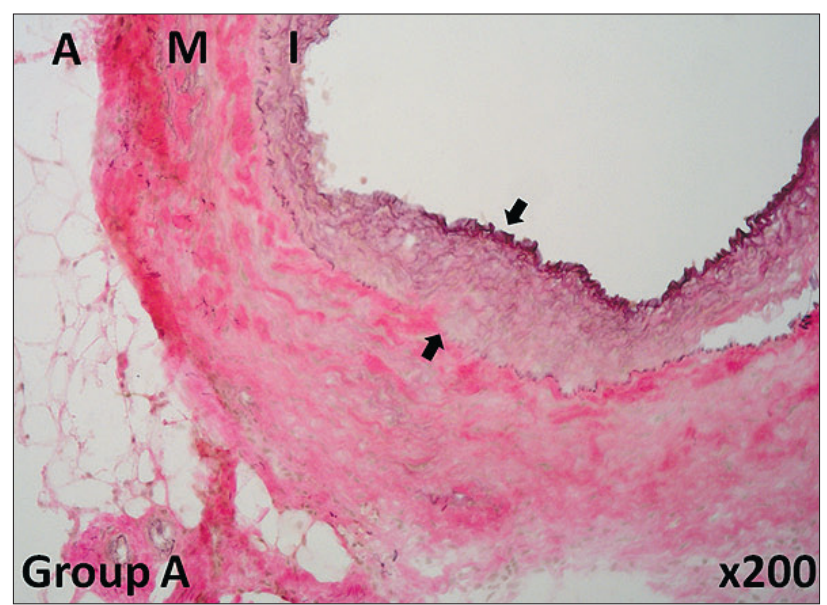

$0.2 \%$ Triton X 100 and phosphate-buffered saline, endogenous biotin was blocked with the Biotin blocking system (Dako Denmark A/S, Glostrup, Denmark). After incubation in 10\% horse serum (prevention of unspecific binding), a primary anti-RT1.B ${ }^{u}$ antibody (MRC-OX3, Cedarlane Laboratories Ltd., Burlington, Ontario, Canada) was applied for $60 \mathrm{~min}$. Endogenous peroxidase was blocked in $0.3 \% \mathrm{H}_{2} \mathrm{O}_{2}$ and $70 \%$ methanol (30 minutes). The specimen was then incubated with a secondary biotinylated horse anti-mouse antibody (Vector Lab, Burlingame, California, USA), followed by incubation with R.T.U. Vectastain Elite ABC Reagent (Vector Lab, Burlingame, California, USA), followed by 5 min incubation with Dako Liquid DAB+ Substrate-Chromogen System (Dako Denmark A/S, Glostrup, Denmark). Finally, the specimens were counterstained and dipped in Entellan@

\section{Statistical analysis}

Comparisons of intimal and medial thicknesses and numbers of lymphocytes and Lewis MHC class II positive cells between the experimental groups were performed with analysis of variance (ANOVA), followed by the Tukey HSD Multiple Comparisons test. $P$ values less than .05 were considered significant. The values in the text and tables are expressed as the mean \pm standard deviation (SD).

\section{Results}

\section{Immunosuppression}

The mean blood level of tacrolimus, measured on day 30 after venous arterialisation, was $6.10 \pm 0.90 \mathrm{ng} / \mathrm{mL}$ in group $\mathrm{B}$, and $3.50 \pm 0.59 \mathrm{ng} / \mathrm{mL}$ in group $\mathrm{C}$, respectively. The difference between both immunosuppressed groups was statistically significant $(\mathrm{p}<0.001)$.

\section{Graft patency}

No venous graft thromboses or occlusions were observed in any of the animals on day 30 after arterialisation.

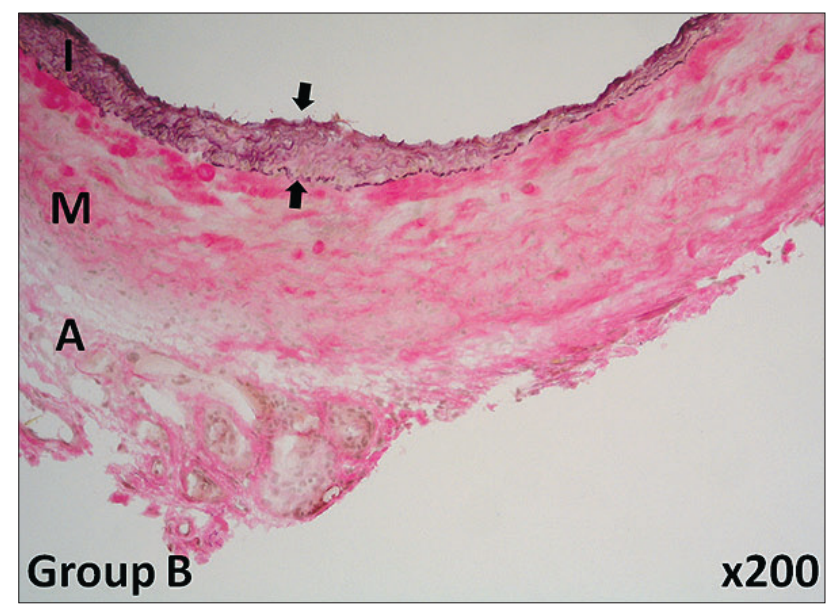

Fig. 2. Representative light microscopic features of non-treated veins (group A) and veins treated with tacrolimus at higher dose (group B) obtained 30 days after implantation to the infrarenal abdominal aorta. Both slides are stained with a Van Gieson with elastica stain. The process of arterialization in both groups was represented by intimal hyperplasia and formation of smooth muscle cells layers in the tunica media. Intimal proliferation (marked by black arrows) was inhibited by tacrolimus in all treated animals.

I - tunica intima, M - tunica media, A - tunica adventitia. 


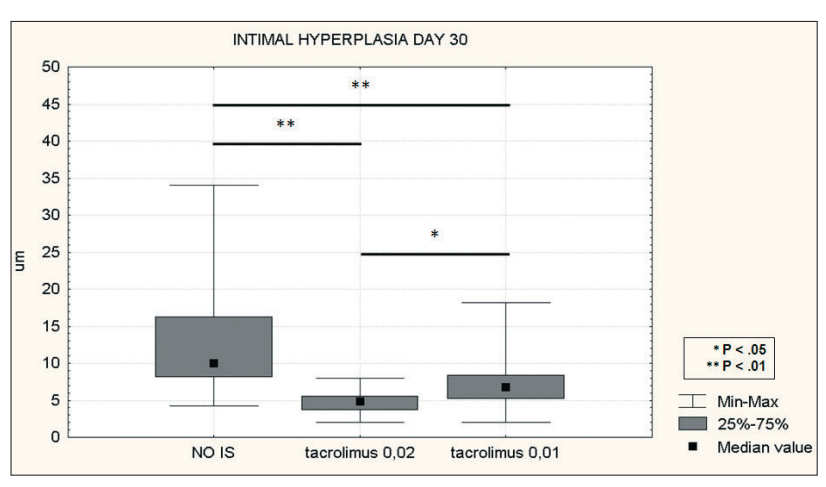

Fig. 3. The intimal thickness of veins treated with tacrolimus was significantly lower $(P<.01)$ compared to the non-treated veins 30 days after their arterialisation. NO IS - no immunosuppression group A.

Tunica intima

In all animal groups, 30 days after arterialisation, the luminal surface of the venous grafts was covered by a monolayer of endothelial cells (Fig. 1). Hyperplasia of the subendothelial neointima developed in all veins during that time period (Fig. 2). In arterialised veins with no treatment (group A) was the mean intimal thickness $12.7 \pm 7.0 \mu \mathrm{m}$. In veins treated with tacrolimus we observed statistically significant reduction of intimal hyperplasia when compared to untreated veins in group $A(p<0.01)$. Moreover, intimal thickness in veins with higher dose of tacrolimus $(5.0 \pm 1.0 \mu \mathrm{m})$ was statistically lower $(\mathrm{p}<0.05)$ when compared to veins with lower dose of tacrolimus $(7.0 \pm 3.0 \mu \mathrm{m})$ (Tab. 1, Fig. 3)

\section{Tunica media}

In all venous grafts led the process of adaptation to arterial pressure to the formation of multiple smooth muscle cell layers 30 days after arterialisation. Medial thickness in animals treated with higher (group B) as well as lower (group C) dose of tacrolimus $(95.9 \pm 33.3 \mu \mathrm{m}$ and $102.3 \pm 31.0 \mu \mathrm{m}$, respectively) did not statistically differ from medial thickness in animals with no treatment (103.2 $\pm 24.6 \mu \mathrm{m})$ (Tab. 1).

\section{Tunica adventitia}

The degree of adventitial infiltration by CD4+, CD8+ and Lewis MHC class II cells did not differ between non-treated and immunosuppressed arterialised veins (Tab. 1).

\section{Discussion}

The present study examined the effect of intramuscular application of tacrolimus on the development of neointimal hyperplasia and medial thickening in arterialised vein grafts. Tacrolimus was chosen as it represent a promising compound for the use in drug-eluting stents as well as it was successfully used to inhibit acute rejection in our previous arterial and venous transplantation models $(18,19)$.

In this experiment we demonstrated an inhibitory effect of tacrolimus on the development of intimal hyperplasia in veins one month after their implantation to arterial system. This inhibitory effect was dose dependent and was present even when tacrolimus mean blood levels were about $3 \mathrm{ng} / \mathrm{mL}$.

Inhibition of intimal hyperplasia by tacrolimus was recently observed in porcine coronary model. Hamada et al observed 4 weeks after implantation of tacrolimus-eluting stents a significantly lower neointimal formation when compared to bare-metal stents (13). Densitometric analysis of Western blotting of isolated protein from porcine coronary arteries 4 weeks after stenting demonstrated that the expression of calcineurin, nuclear factor of activated $\mathrm{T}$ cell and interleukin-2 was significantly lower.

Our previous experiment confirmed positive effect of tacrolimus, at same blood level used in this study, on development of the intimal proliferation 30 days following arterialisation of venous allografts (19). The degree of intimal proliferation, a specific feature of vein arterialisation, did not differ between syngeneic venous grafts and allogeneic venous grafts treated by tacrolimus. Contrary, there were only minimal signs of intimal hyperplasia in non-treated allogeneic veins as a result of venous wall destruction by host immune system. Moreover, in arterial allografts, tacrolimus at same dosage was sufficient to inhibit the overexpression of neointimal proliferation, a specific feature of arterial wall rejection (18).

In this study, all treated vein grafts were covered by monolayer of endothelial cells 4 weeks after arterialisation. We haven't observed any delayed re-endothelialisation when compared to the non-treated animals. This is in accordance with a work of Steffel et al (20) who have clearly demonstrated that tacrolimus neither affects tissue factor expression in human aortic endothelial cells nor inhibits endothelial cell proliferation.

All the veins in the present study developed proliferation of vascular smooth muscle cells in medial layer. This proliferation contributed to an increase in vascular wall thickness and mass, the

Tab. 1. The parameters of rats iliolumbar venous grafts 30 days after their implantation to the abdominal aorta.

\begin{tabular}{|c|c|c|c|c|c|c|c|}
\hline \multirow{2}{*}{ Group } & \multirow{2}{*}{ IS } & \multicolumn{2}{|l|}{ Intima* } & Media* & \multicolumn{2}{|l|}{ Adventitia** } & \multirow[b]{2}{*}{ CD4+ cells } \\
\hline & & Thickness & Endothelial layer & Thickness & MHC class II+ cells & CD8+ cells & \\
\hline $\mathrm{A}$ & NO & $12.7 \pm 7.0$ & + & $103.2 \pm 24.6$ & $16.6 \pm 7.5$ & $0.8 \pm 1.7$ & $12.5 \pm 7.7$ \\
\hline B & $\begin{array}{c}\text { FK506 } \\
0.2 \mathrm{mg} / \mathrm{kg}\end{array}$ & $5.0 \pm 1.0^{1,2}$ & + & $95.9 \pm 33.3$ & $14.5 \pm 5.7$ & $0.9 \pm 1.3$ & $11.9 \pm 5.0$ \\
\hline $\mathrm{C}$ & $\begin{array}{c}\text { FK506 } \\
0.1 \mathrm{mg} / \mathrm{kg}\end{array}$ & $7.0 \pm 3.0^{1}$ & + & $102.3 \pm 31.0$ & $13.2 \pm 6.4$ & $0.7 \pm 1.1$ & $6.5 \pm 3.3$ \\
\hline
\end{tabular}

${ }^{1}$ The intimal thicknesses in veins treated with tacrolimus (group B, group C) were statistically lower ( $<0.01$ ) when compared to the non-treated veins (group A), ${ }^{2}$ The intimal thickness in veins treated with tacrolimus at higher dose (group B) was statistically lower $(\mathrm{p}<0.05)$ when compared to veins treated with tacrolimus at lower dose (group C), * The intimal and medial thicknesses are expressed in $\mu \mathrm{m},{ }^{* *}$ Numbers of MHC class II, CD8 and CD4 positive cells in one eyepiece at original magnification $\mathrm{x} 1000$, IS - immunosuppression. 
other typical feature of venous arterialisation (21). Previous cell cultures experiments have demonstrated the anti-proliferative effect of tacrolimus on vascular smooth muscle cells and the calcineurin/nuclear factor of activated $\mathrm{T}$ cell signaling pathway in vitro $(13,17)$. Despite observed tendency of medial layer thinning in higher-dosage tacrolimus group, this thinning was not of statistical significance when compared to non-treated veins.

There were no differences in CD4+, CD8+ and MHC class II positive cells adventitial layer infiltration between treated and non-treated arterialised vein grafts in our study. Schachner et al (15) have influenced the formation of intimal hyperplasia by local application of sirolimus (rapamycin) in vein-to-artery implantation model in mouse. They observed association between reduction of vein graft disease and decreased amount of infiltration of adventitial layer by CD8 + cells. We haven't observed any difference in CD8 + infiltration between treated and non-treated animals. This could be explained by the fact that sirolimus was used locally in pluronic gel applied in the perivascular spaces of grafted veins and that sirolimus can contribute to massive T-cell apoptosis (22).

In conclusion, the present study confirmed inhibitory effect of tacrolimus on formation of intimal hyperplasia in the vein-to-artery implantation model. This is in accordance with recent experimental findings that newly developed tacrolimus-eluting stents inhibited neointimal hyperplasia and restenosis after stenting. Thus, tacrolimus may represent a potent drug in the therapeutic approaches to inhibit accelerated intimal hyperplasia in cardiovascular surgery in case that local, efficacious drug delivery mechanism will be developed.

\section{References}

1. Wallitt EJ, Jevon M, Hornick PI. Therapeutics of vein graft intimal hyperplasia: 100 years on. Ann Thorac Surg 2007; 84 (1): 317-323.

2. Raja SG, Haider Z, Ahmad M, Zaman H. Saphenous vein grafts: to use or not to use? Heart Lung Circ 2004; 13 (4): 403-409.

3. Westerband A, Crouse D, Richter LC et al. Vein adaptation to arterialization in an experimental model. J Vasc Surg 2001; 33 (3): 561-569.

4. Chlupac J, Filova E, Bacakova L. Blood Vessel Replacement: 50 years of Development and Tissue Engineering Paradigms in Vascular Surgery. Physiol Res 2009; 58 (Suppl. 2): S119-S139.

5. Angelini GD, Passani SL, Breckenridge IM, Newby AC. Nature and pressure dependence of damage induced by distension of human saphenous vein coronary artery bypass grafts. Cardiovasc Res 1987; 21 (12): 902-907.

6. Leask RL, Butany J, Johnston KW et al. Human saphenous vein coronary artery bypass graft morphology, geometry and hemodynamics. Ann Biomed Eng 2005; 33 (3): 301-309.

7. Mitra AK, Gangahar DM, Agrawal DK. Cellular, molecular and immunological mechanisms in the pathophysiology of vein graft intimal hyperplasia. Immunol Cell Biol 2006; 84 (2): 115-124.
8. Morice MC, Serruys PW, Sousa JE et al. A randomized comparison of a sirolimus-eluting stent with a standard stent for coronary revascularization. N Engl J Med 2002; 346 (23): 1773-8170.

9. Stone GW, Ellis SG, Cox DA et al. A polymer-based, paclitaxel-eluting stent in patients with coronary artery disease. N Engl J Med 2004; 350 (3): 221-231.

10. Moses JW, Leon MB, Popma JJ et al. Sirolimus-eluting stents versus standard stents in patients with stenosis in a native coronary artery. $\mathrm{N}$ Engl J Med 2003; 349 (14): 1315-1323.

11. Babapulle MN, Joseph L, Belisle P et al. A hierarchical Bayesian meta-analysis of randomised clinical trials of drug-eluting stents. Lancet 2004; 364 (9434): 583-591.

12. Stone GW, Moses JW, Ellis SG et al. Safety and efficacy of sirolimus- and paclitaxel-eluting coronary stents. N Engl J Med 2007; 356 (10): 998-1008.

13. Hamada N, Miyata $\mathbf{M}$ eto $\mathbf{H}$ et al. Tacrolimus-eluting stent inhibits neointimal hyperplasia via calcineurin/NFAT signaling in porcine coronary artery model. Atherosclerosis 2010; 208 (1): 97-103.

14. Thomson AW, Bonham CA, Zeevi A. Mode of action of tacrolimus (FK506): molecular and cellular mechanisms. Ther Drug Monit 1995; 17 (6): 584-591.

15. Schachner T, Zou Y, Oberhuber A et al. Local application of rapamycin inhibits neointimal hyperplasia in experimental vein grafts. Ann Thorac Surg 2004; 77 (5): 1580-1585.

16. Hafizi S, Mordi VN, Andersson KM et al. Differential effects of rapamycin, cyclosporine A, and FK506 on human coronary artery smooth muscle cell proliferation and signalling. Vascul Pharmacol 2004; 41 (4-5): 167-176.

17. Matter CM, Rozenberg I, Jaschko A et al. Effects of tacrolimus or sirolimus on proliferation of vascular smooth muscle and endothelial cells. J Cardiovasc Pharmacol 2006; 48 (6): 286-292.

18. Matia I, Lodererova A, Adamec M. Delayed administration of FK 506 is sufficient to suppress acute rejection changes after aortal transplantation in rats. Transpl Int 2007; 20 (4): 371-380.

19. Matia I, Varga M, Lodererova A, Adamec M. The Positive Effect of Immunosuppression on Adaptation of Venous Allografts to Arterialisation in Rats. Eur J Vasc Endovasc Surg 2009.

20. Steffel J, Latini RA, Akhmedov A et al. Rapamycin, but not FK-506, increases endothelial tissue factor expression: implications for drug-eluting stent design. Circulation 2005; 112 (13): 2002-2011.

21. Kwei S, Stavrakis G, Takahas $M$ et al. Early adaptive responses of the vascular wall during venous arterialization in mice. Am J Pathol 2004; 164 (1): 81-89.

22. Li Y, Li XC, Zheng XX et al. Blocking both signal 1 and signal 2 of T-cell activation prevents apoptosis of alloreactive T cells and induction of peripheral allograft tolerance. Nat Med 1999; 5 (11): 1298-1302.

Received April 11, 2011. Accepted September 20, 2011. 